\title{
Ultrasonographic study of comparison of prostate volume and post void residual urine with age in north Indian population
}

\author{
Tahsin Munsif', Syed Shabeeh Haider², Vineeta Tewari ${ }^{3}$, Mariyam Fatima ${ }^{4}$, \\ Pradeep Kumar Sharma ${ }^{5}$ \\ ${ }^{1}$ Assistant Professor, ${ }^{3}$ Professor, ${ }^{5}$ Professor and Head, Department of Anatomy, Eras Lucknow Medical College, Era \\ University, Lucknow, UP, India, ${ }^{2}$ Associate Professor, Department of Surgery, Eras Lucknow Medical College, Era \\ University, Lucknow, UP, India, ${ }^{4}$ MBBS $1{ }^{\text {ST }}$ Year student, FH Medical College Agra, UP, India
}

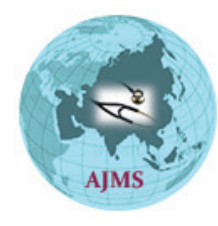

A B S T R A C T

Background: As men's life expectancy increases, benign prostatic hyperplasia (BPH) is the significant cause of morbidity. BPH generally involves the central region of the prostate which gradually enlarges. Due to the central hypertrophic change of prostate the urethra is compressed and urinary outflow obstruction develops. Predictive risk factors associated with chance of developing urinary retention includes age, symptoms, urinary flow rate and prostate size. Estimation of accurate intravesical, residual urine has significant importance and serves as an index of adequacy of bladder emptying. Aims and Objectives: The study aimed to measure the post void residual urine volume with age in Prostate outflow obstruction and compare the prostate volume and post void residual urine with age by ultrasonography. Materials and Methods: The present study was performed in 100 patients. Transrectal ultrasonography was performed using $7.5 \mathrm{MHZ}$ transrectal probe. Prostate volume was calculated with the help of inbuilt software, by measuring 3 dimensions of prostate in transverse and longitudinal sections. Transabdominal suprapubic ultrasound was done to measure post void residual urine. Results: It was seen that in the lower age groups, the prostate size was smaller, while in the higher age group it was higher $(p>0.001)$. Minimum post void residual urine was seen in age group of 4049 years $(3.42-+2.23 \mathrm{ml})$. while maximum mean value was seen in the $70-79$ years of age. Statistically a significant difference in mean was seen among different age groups $(p<0.001)$. Conclusion: There is a significant correlation between age and post void residual urine volume and prostatic volume. The present study showed that PVRUV is a novel accurate non-invasive test for predicting prostate biopsy outcome that can easily be used by clinicians, alone or in combination with Prostate Volume in the decision-making for treatment.

\section{Access this article online}

Website:

http://nepjol.info/index.php/AJMS DOI: $10.3126 /$ ajms.v12i10.37933

E-ISSN: 2091-0576

P-ISSN: 2467-9100

Copyright (c) 2021 Asian Journal of Medical Sciences

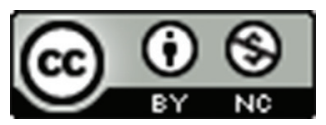

This work is licensed under a Creative Commons Attribution-NonCommercial 4.0 International License.

Key words: Prostate; Prostatic volume; Post void residual urine volume; Bladder outflow obstruction; Lower urinary tract symptoms; Benign prostate hypertrophy

\section{INTRODUCTION}

The prostate is a pyramidal fibromuscular gland which surrounds the prostatic urethra from the bladder base to the membranous urethra. ${ }^{1}$ Prostate develops by ninth week of embryonic life from modified wall of proximal portion of male urethra. At the end of $3^{\text {rd }}$ month of intrauterine life epithelium of prostatic urethra begins to proliferate and forms number of outgrowths that penetrate the surrounding mesenchyme. These buds form prostate gland. ${ }^{2}$ A healthy prostate is shaped like an inverted rounded cone. ${ }^{3}$ It surrounds the urethra just below the urinary bladder and can be felt during rectal examination. In men at 20 to 30 years of age weight of the prostate is 20 grams, however mean prostatic weight increases after the age of 50 years. ${ }^{4}$ 
As life expectancy increases, benign prostatic hyperplasia $(\mathrm{BPH})$ is the significant cause of morbidity. BPH generally involves the central region of the prostate which gradually enlarges. Due to the central hypertrophic change of prostate the urethra is compressed and urinary outflow obstruction develops. With time bladder may become hypertrophied in response to urinary outflow obstruction. ${ }^{3}$ The natural history of BPH studied by population-based study in Olmstead County demonstrated that lower urinary tract symptoms associated with $\mathrm{BPH}$ increases with age. Men with symptomatic $\mathrm{BPH}$ and who are not treated have a $2.5 \%$ higher risk for developing urinary retention. Predictive risk factors associated with chance of developing urinary retention includes age, symptoms, urinary flow rate and prostate size. $^{5}$

The clinical diagnosis of benign prostatic hyperplasia is made by assessment of prostate size or volume and reduced urinary flow rate. Benign prostatic enlargement (BPE), bladder outlet obstruction (BOO) and lower urinary tract symptoms (LUTS) is the basic triad for clinical diagnosis of benign prostatic hyperplasia. About 50\% of men with histologically proven BPH have moderate to severe lower urinary tract symptoms (LUTS) that are symptoms related to storage and voiding of urine. ${ }^{6}$ Estimation of accurate intravesical residual urine volume has significant importance and serves as an index of adequacy of bladder emptying. Ultrasonography is useful to confirm this measurement noninvasively in patients and it avoids discomfort, urethral trauma and urinary tract infection. This procedure avoids need for catheterization and permits physiological assessment and allows for repeated examination without fear and anxiety for the patient. ${ }^{7}$ Residual urine volume (RUV) in persons above 50 years is used for objective assessment of prostate size. However, to decide what is abnormal it is necessary to agree on what can be considered normal. Clinical testing with uroflowmetry and assessment of postvoid residual urine can help the clinician determine the severity of bladder outflow obstruction. ${ }^{4}$

Ultrasonography of prostate is the investigation that enables us to visualize the prostate gland directly and is one of the commonest diagnostic modalities performed nowadays. It can be done using the suprapubic abdominal approach as well as transrectal approach. ${ }^{8}$

Although residual urine volume measurement is frequently used to evaluate prostate size, only few studies have included sufficient age matched control. This study is conducted to assess the distribution of post void residual urine volume and its relationship with prostate size.

\section{MATERIALS AND METHODS}

This study was carried out in the Department of Anatomy in collaboration with Department of Surgery and Department of Radiology Era University, Lucknow. This was a prospective observational study. Nature of study was hospital based cross- sectional study. All the male patients above 40 years of age with lower urinary tract symptoms visiting the hospital were included in the study. Present study was performed on 100 patients. Age of the patients varied from 40-79years of age. Patients who had not given consent, below 40 years of age, bladder volume $>540 \mathrm{ml}$, critically ill subjects, patients on anticholinergics, patients with UTI or neuropathic bladder were excluded. Ethical clearance was taken from institutional ethical committee. All the patients were subjected to history taking, clinical examination, per rectal examination, Transrectal and transabdominal ultrasonography was performed. Transrectal ultrasonography was performed using 7.5 MHZ transrectal probe. Prostate volume and transition zone volume were calculated with the help of inbuilt software, by measuring 3 dimensions of prostate in transverse and longitudinal sections. Patients were directed to empty the bladder. Transabdominal supra pubic ultrasonography was performed for residual urine volume. ${ }^{9}$

\section{Statistical Analysis}

The data was analyzed using statistical package for social sciences version 15.0. Intergroup comparison for mean values was made using ANOVA. The confidence limit was $95 \%$ hence $\mathrm{p}$ value less than 0.05 indicated statistically significant difference.

\section{RESULTS}

The age of patients varied from 40-80 years. Maximum number of patients were between 60-69 years followed by $70-79$ years of age (30\%). There were $12 \%$ patients in the age group of $40-49$ years and $24 \%$ were in the age group of 50-59 years. Thus, it was seen that complaints of prostatic disease were common in higher age group (Table 1).

In the age group of 40-49 years only irritative symptoms were observed. In the 50-59 years of age obstructive symptoms took over irritative symptoms. In 60-79 years of age both obstructive as well as irritative symptoms were seen (Table 2).

Mean prostate size in the age group of 40-49 years was found to be $20.92 \pm 2.57 \mathrm{gm}$ (range 18-25). In the age group of 50-59 years the range was found to be 26-40 grams. In 60-69 years of age, it was measured as $59.15 \pm 9.35 \mathrm{gm}$ and in the 70-79 years of age it was found to be $64.93 \pm 8.45$ 
grams. (Table 3). This shows a significant difference in mean size in different age groups. It was seen that in the lower age groups the prostate size was smaller while in the higher age groups its size was larger $(\mathrm{p}<0.001)$.

Minimum post void residual urine volume was seen in the age group of $40-49$ years $(3.42 \pm 2.23 \mathrm{ml})$ while maximum mean value was seen in 70-79 years of age (Table 4 and Figure 1). Statistically a significant difference in mean post void residual urine volume was seen among different age groups $(\mathrm{p}<0.001)$.

In the present study it was also observed that as the size of prostate increases with age, the post void residual urine volume also increases (Figure 2).

\begin{tabular}{lccc}
\multicolumn{4}{l}{ Table1: Age Distribution $(\mathbf{n}=\mathbf{1 0 0})$} \\
\hline S.No & Age group & No of patients & Percentage \\
\hline 1 & $40-49$ & 12 & 12 \\
2 & $50-59$ & 24 & 24 \\
3 & $60-69$ & 34 & 34 \\
4 & $70-79$ & 30 & 30 \\
\hline
\end{tabular}

\begin{tabular}{llc}
\hline \multicolumn{3}{l}{ Table 2: Distribution of patients on most } \\
common symptoms and age group
\end{tabular}

\begin{tabular}{|c|c|c|c|}
\hline $\begin{array}{l}\text { Age group } \\
\text { (in years }\end{array}$ & $\begin{array}{c}\text { No of } \\
\text { patients }\end{array}$ & $\begin{array}{c}\text { Mean prostate size with } \\
\text { age }\end{array}$ & SD \\
\hline $40-49$ & 12 & 20.92 & 2.57 \\
\hline $50-59$ & 24 & 31.75 & 3.76 \\
\hline $60-69$ & 34 & 59.15 & 9.35 \\
\hline $70-79$ & 30 & 64.93 & 8.45 \\
\hline Total & 100 & 49.72 & 18.26 \\
\hline
\end{tabular}

\begin{tabular}{|c|c|c|c|c|}
\hline $\begin{array}{l}\text { Age group } \\
\text { (in years) }\end{array}$ & $\begin{array}{c}\text { No of } \\
\text { patients }\end{array}$ & $\begin{array}{c}\text { Mean post void } \\
\text { residual urine } \\
\text { volume with age } \\
(\mathrm{ml})\end{array}$ & SD & Range \\
\hline $40-49$ & 12 & 3.42 & 2.23 & $0-6$ \\
\hline $50-59$ & 24 & 55.75 & 13.34 & $34-78$ \\
\hline $60-69$ & 34 & 113.06 & 25.83 & $62-148$ \\
\hline $70-79$ & 30 & 123.13 & 21.91 & $94-171$ \\
\hline Total & 100 & 89.17 & 45.96 & $0-171$ \\
\hline
\end{tabular}

\section{DISCUSSION}

The voiding dysfunction due to enlargement of prostate gland and bladder outlet obstruction (BOO) is known as lower urinary tract symptoms (LUTS). It has also been commonly referred to as prostatism, but this term is less popular. The prevalence of LUTS increases with age, and estimates vary widely depending on the definitions and cohorts studied, have a major impact on health-related quality of life..$^{10,11}$

In the present study the prostate volume showed a significant increase in mean size in different age groups. It was seen that in the lower age groups the prostate size was smaller while in higher age groups the size was larger $(\mathrm{p}<0.001)$. Awadhi et al., ${ }^{12}$ in their study also found significant correlation between Prostatic volume and age.

Jinsung park et al., ${ }^{13}$ in their study in Korean population also observed that PV increases with age which is in accordance with the present study.

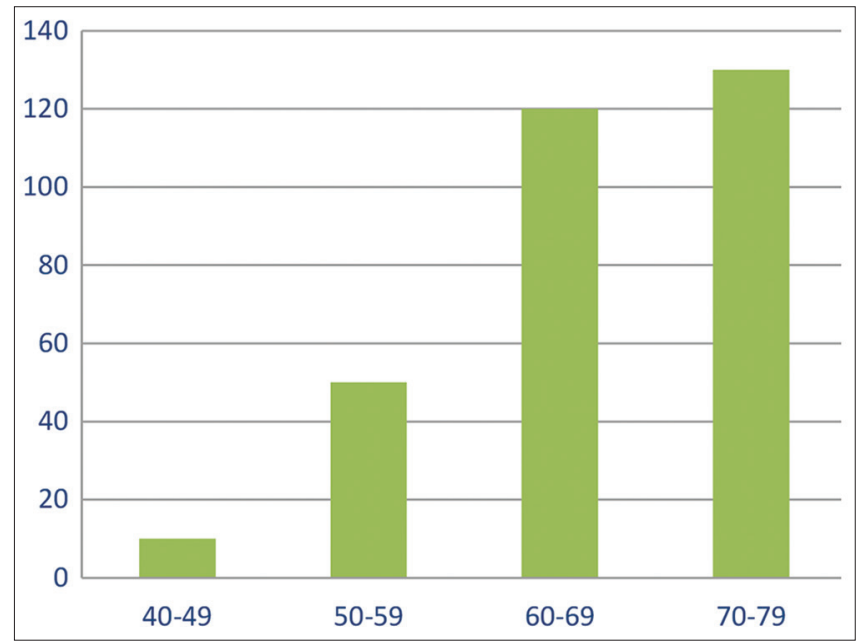

Figure 1: Comparison of post void residual urine with age

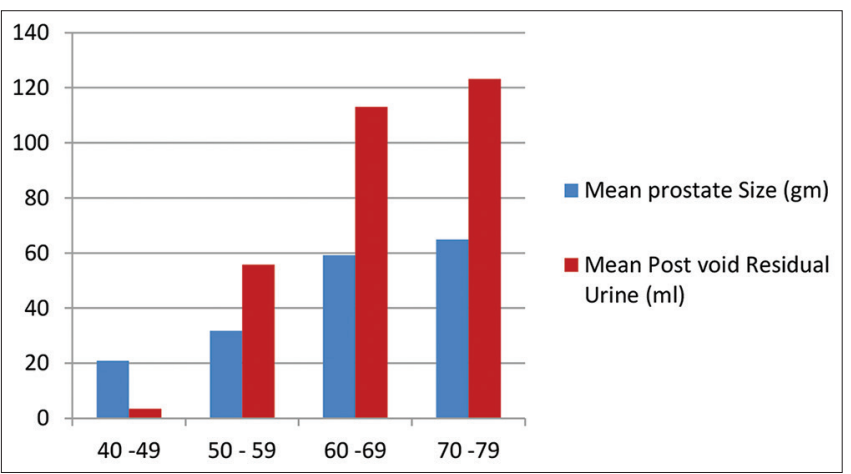

Figure 2: Comparison of mean prostate size with mean residual post void urine 
In this study the post void residual urine volume was maximum in the age group 70-79 years and it was minimum in 40-49 years of age. statistically a significant difference in PVUR was seen in different in age groups. In this study the mean post void residual urine volume (PVR) was measured as $89.17+-45.96 \mathrm{ml}, 24$ patients showed residual volume less than $60 \mathrm{ml} .34$ patients had PVR between $62-148 \mathrm{ml}$ and 30 patients had volume more than $100 \mathrm{ml}$. The increase in prostate volume (PV) is associated with elevated post void residual volume (PVR) significantly (P value 0.001). This is in accordance with Safa Hussain et al. ${ }^{14}$

Brijendra Raj Joshi et al., ${ }^{8}$ in their study done in population of Nepal concluded that there was no significant increase in post void residual urine with age. They also correlated the prostate volume with post void residual urine and observed that PVUR increases as the prostate volume increases which is in accordance with present study.

Kolman et al., ${ }^{15}$ found a significant correlation between PVR and prostate volume. They also compared the PVR with age and found no co-relation between them which is not in accordance with the present study

\section{CONCLUSION}

There is a significant correlation between age and post void residual urine volume. Also, there is a significant correlation between post void residual urine volume and prostate volume. The present study showed that PVRUV is a novel accurate non-invasive test for predicting prostate biopsy outcome that can easily be used by clinicians, alone or in combination with Prostate Volume in the decisionmaking. Bladder scanning and real-time transabdominal ultrasound is non-invasive and has no risk of ionizing radiation. The post-void residual volume can be used as a diagnostic tool to evaluate for underlying pathology. In addition to history and physical examination, it can help to identify and diagnose urinary retention, and therefore determine the proper management, and prevent further disability or death.

\section{ACKNOWLEDGEMENT}

The authors take this opportunity to thank Department of Anatomy, Surgery, and Radiology for their whole hearted support for this study.

\section{REFERENCES}

1. Susan Standring. Gray's Anatomy. $40^{\text {th }}$ ed. U.K.: Elsevier, 2009, 1255.
2. T.W. Sadler. Langman's Medical Embryology. $12^{\text {th }}$ ed. U.S.: Lippincott Williams and Wilkins, 2016, 241.

3. Richard L. Drake. Gray's Anatomy for students. $3^{\text {rd }}$ ed. U.K.: Elsevier, 2013, 474.

4. Townsend CM, Beauchamp RD, Evers BM. Sabiston textbook of surgery. $18^{\text {th }}$ ed. Philadelphia: WB Saunders, 2007. 2269. https://doi.org/10.1007/s10350-008-9293-5

5. Anwari M, Allen $\mathrm{C}$ and Born A. Laproscopic Nissen fundoplication: Laproscopic dissection technique and results. Hepatogastroenterology. 1997; 44: 4-10.

6. Wasserman NF. Benign Prostatic Hyperplasia: A review and ultrasound classification. The radiologic clinics of North America, Prostate gland. 2006; 44: 689-710.

https://doi.org/10.1016/j.rcl.2006.07.005

7. Shadab M and Arpita M. Prostate Size Evaluation By Sonography and Post Void Residual Urine Volume - Comparative Study. National Journal of Medical and Dental Research. 2019; 8(1): 696-699.

8. Joshi B R and Dwivedi SK. Sonographic Comparison of Prostate Size with Post void Residual Urine Volume. International Journal of Radiology. 2019; 6(1): 208-211. https://doi.org/10.17554/j.issn.2313-3406.2019.06.60

9. Byun SS, Kim HH, Lee E, Paick JS, Kamg W and Oh SJ. Accuracy of bladder volume determinations by ultrasonography: are they accurate over entire bladder volume range? Urology. 2003; 62(4): 656-660.

https://doi.org/10.1016/S0090-4295(03)00559-4

10. L Martin SA, Haren MT, Marshall VR, Lange $K$ and Wittert GA. Prevalence and factors associated with uncomplicated storage and voiding lower urinary tract symptoms in community-dwelling Australian men. World J Urol. 2011; 29: 179-184.

https://doi.org/10.1007/s00345-010-0605-8

11. Kupelian V, Wei JT and O'Leary MP. Prevalence of lower urinary tract symptoms and effect on quality of life in a racially and ethnically diverse random sample: the Boston Area Community Health (BACH) Survey. Arch Intern Med. 2006; 166: 2381-2387.

https://doi.org/10.1001/archinte.166.21.2381

12. Awadia G, Ikhlas A H, Marwa M, Duha A and Salah A. Sonographic Assessment of Residual Urine Volume in Benign Prostatic Hyperplasia patients in Sudan. Global Advanced Research Journal of Medicine and Medical Sciences. 2017; 6(10): 257-266.

13. Jinsung $P$, Dong-G L, Beomseok $S$, Sung $Y C$, In $H C$, Sung $H P$, et al. Establishment of Reference Ranges for Prostate Volume and Annual Prostate Volume Change Rate in Korean Adult Men: Analyses of a Nationwide Screening Population. Journal of Korean Med Sci. 2015; 30: 1136-1142. https://doi.org/10.3346/jkms.2015.30.8.1136

14. Safaa Husain Ibrahim $H$, Ali Yaseen M, and Abdel Raof S. Correlation between the Size of the Prostate, Post Void Residual Volume, PSA Level and IPSS in Men with LUTS in Three Major Urology Centers in Khartoum. International Journal of Surgical Research. 2020; 9(1): 1-8.

15. Christopher K, Girman CJ, Jacobsen SJ and Lieber MM. Distribution of post void residual urine volume in randomly selected men. The Journal of Urology. 1999; 161(1): 122-127. https://doi.org/10.1016/S0022-5347(01)62081-0 
Author's Contribution:

TM- Concept and design of study, prepared and drafted the manuscript; SH- Data collection \& Statistical analysis and interpretation of results; VT- Concept, coordination and manuscript preparation; MF- Review of literature and Formatting of manuscript; PK- Revision of manuscript.

Work Attributed to:

Era's Lucknow Medical College, Era University, Lucknow, Uttar Pradesh, India.

Orcid ID:

Dr Tahsin Munsif- (1) https://orcid.org/0000-0001-5853-1080

Dr Syed Shabeeh Haider- iD https://orcid.org/0000-0002-2042-1502

Dr Vineeta Tewari- (1) https://orcid.org/0000-0003-1695-0230

Mariyam Fatima- https://orcid.org/0000-0003-2008-438X

Dr PK Sharma- (i) https://orcid.org/0000-0001-5185-2746 